\title{
вмJ Global Health Disability status, intimate partner violence and perceived social support among married women in three districts of the Terai region of Nepal
}

\author{
Jhumka Gupta, ${ }^{1}$ Lauren F Cardoso, ${ }^{2}$ Gemma Ferguson, ${ }^{3}$ Binita Shrestha, ${ }^{3}$ \\ Prabin Nanicha Shrestha, ${ }^{3}$ Courtney Harris, ${ }^{1}$ Nora Groce, ${ }^{4}$ Cari Jo Clark ${ }^{5}$
}

\begin{abstract}
To cite: Gupta J, Cardoso LF, Ferguson G, et al. Disability status, intimate partner violence and perceived social support among married women in three districts of the Terai region of Nepal. BMJ Glob Health 2018;3:e000934. doi:10.1136/ bmjgh-2018-000934
\end{abstract}

Handling editor Sanni Yaya

Received 4 May 2018 Revised 6 September 2018 Accepted 14 September 2018

Check for updates

(C) Author(s) (or their employer(s)) 2018. Re-use permitted under CC BY-NC. No commercial re-use. See rights and permissions. Published by BMJ.

${ }^{1}$ Department of Global and Community Health, College of Health and Human Services, George Mason University, Fairfax, Virginia, USA

${ }^{2}$ School of Policy and Practice, University of Pennsylvania, Philadelphia, Pennsylvania, USA ${ }^{3}$ Equal Access International, San Francisco, California, USA

${ }^{4}$ Leonard Cheshire Research Centre, Department of

Epidemiology and Public Health, University College London,

London, UK

${ }^{5}$ Department of Global Health, Rollins School of Public Health, Emory University, Atlanta, Georgia, USA

Correspondence to Professor Jhumka Gupta; jgupta4@gmu.edu

\section{ABSTRACT}

Introduction Women living with disabilities are disproportionately vulnerable to intimate partner violence (IPV). Existing research on the topic largely takes place in high-income settings and treats disability as a dichotomous experience - an individual either has a disability or does not. Disability experiences, however, are diverse such that some individuals face minimal impairment, while for others impairment can be severe. With this spectrum in mind, this study sought to examine the associations between severity of disability impairment, past-year IPV, past-year in-law violence and perceived social support among married women in Nepal. Methods Baseline data (2016) from a randomised controlled trial aiming to reduce IPV among women aged 18-49 $(n=1800)$ were analysed using generalised estimating equations logistic regressions to assess associations.

Results Women with severe impairment reported higher levels of physical and/or sexual, emotional, economic and in-law violence than women without a disability (adjusted $\mathrm{OR}(\mathrm{AOR})=1.68,95 \% \mathrm{Cl} 1.04$ to $2.72 ; \mathrm{AOR}=1.65,95 \% \mathrm{Cl}$ 1.03 to $2.65 ; \mathrm{AOR}=1.75,95 \% \mathrm{Cl} 1.02$ to $3.02 ; \mathrm{AOR}=2.80$, $95 \% \mathrm{Cl} 2.53$ to 5.11 , respectively). Differences in IPV between women reporting some impairment versus no disability were observed for economic (AOR=1.47, 95\% Cl 1.11 to 1.94$)$ and in-law violence ( $\mathrm{AOR}=1.50,95 \% \mathrm{Cl} 1.07$ to 2.10). Women with severe or some impairment versus no disability were less likely to perceive their in-laws as supportive.

Conclusion Disability status was associated with increased vulnerability to IPV. A gradient was observed; the highest levels of IPV were experienced by women with severe impairment, followed by some impairment. Future research should examine the mechanisms driving such observations.

\section{INTRODUCTION}

According to the WHO, $15 \%$ of the world's population ages 15 and older lives with some form of disability, a figure closer to $18 \%$ in lower income countries. ${ }^{1}$ While historically conceptualised as solely a medical condition,

\section{Key questions}

What is already known?

- Women living with disabilities are disproportionately vulnerable to intimate partner violence.

- Sources of social support are limited for women with disabilities who have experienced intimate partner violence.

- Research on this topic is largely concentrated in high-income countries and treats disability as dichotomous, despite the existing spectrum of disability impairments.

\section{What are the new findings?}

- In Nepal, disability status is associated with increased vulnerability to intimate partner violence; the strength of the association increases with the severity of impairment.

- Perceived social support also varies by severity of impairment such that women with a severe or some impairment are less likely to report having supportive in-laws.

\section{What do the new findings imply?}

- The needs of women living with disabilities should be integrated into ongoing intimate partner violence prevention and intervention work in low-income countries to destigmatise disability status, ensure services are accessible to women with disabilities and account for the variation in intimate partner violence experiences among women with different levels of impairment.

disability status is increasingly framed as an important social determinant of health. ${ }^{2}$ Research from multiple global regions illustrates that people living with disabilities experience lower educational attainment, ${ }^{3}$ less income, ${ }^{4}$ lower social status ${ }^{5}$ and worse health outcomes ${ }^{5}$ than those without disabilities. Among the numerous mechanisms that may underlie the associations between poorer health and disability status, inaccessible health services, social exclusion, poverty 
and societal marginalisation have been noted as important drivers. ${ }^{1}$

In addition to the aforementioned health and social outcomes, a disproportionate number of women living with disabilities experience intimate partner violence (IPV) ${ }^{67}$ Within Nepal, two existing studies suggest that women with disabilities face high levels of IPV. A 2015 study with 475 Nepalese women living with a disability found that $57.7 \%$ reported experiencing lifetime emotional, physical or sexual violence, of whom $39 \%$ reported violence perpetrated by husbands. ${ }^{8}$ In this sample, women living with disabilities who were younger, without children, employed and lacking autonomy in reproductive healthcare decisions experienced more violence. In another smaller scale report, 15 out of 20 blind women in Kathmandu reported experiencing some form of sexual abuse perpetrated by friends, family members or teachers. ${ }^{9}$ Likewise, a study in Mumbai, India, documented that among 123 ever-married women with disabilities, nearly 1 in 4 reported experiencing pastyear physical IPV $(22.0 \%)$ and emotional IPV (22.8\%). Additionally, sexual violence $(10.6 \%)$ and in-law violence $(13.8 \%)$ were reported. ${ }^{10}$ These data, coupled with the qualitative research from Bangladesh ${ }^{10}{ }^{11}$ and India, ${ }^{12}$ illustrate the multiple forms of violence faced within the marital home and underscore how gender inequity and dependence on male partners or family for care may exacerbate vulnerability to IPV.

As a social determinant of health, disability can manifest in the social exclusion of women with an impairment. ${ }^{13}$ Such isolation, driven in part by stigma towards disability $^{14}$ and lack of socially inclusive services, can also increase women's physical and financial dependence on their partner and increase their vulnerability to IPV. ${ }^{10-12}$ Such dependence may also hinder access to social support, or the help women with disabilities receive or perceive they could receive from people in their social network, for IPV. In the context of IPV, family members are the most common providers of informal support. ${ }^{10}$ However, they can contribute to IPV either by perpetrating abuse or condoning it. ${ }^{1015}$ Given their heightened social isolation and reliance on partners and relatives for care, women with disabilities who experience IPV may also have fewer outlets for disclosure or help-seeking. Fewer opportunities for positive social support may limit access to this potentially beneficial intervention. ${ }^{16}$

Within Nepal, the overall prevalence of physical or sexual IPV mirrors the global average, with one in three women reporting such lifetime IPV. ${ }^{17}$ There is growing research on the risk and protective factors that influence women's vulnerability to IPV in Nepal, and such work has identified women and girls' lower social status, socially restricted ability to achieve higher educational attainment, lower access to financial resources and high societal acceptability of violence against women as important determinants. ${ }^{18}$ Despite high IPV levels among women living with disabilities in Nepal, little is known regarding how disability status, including degree of functional limitations, may confer additional risks for experiencing IPV. Such research is important to inform IPV prevention and response programming and to meet the Sustainable Development Goals, which call for both the elimination of violence against women and girls and disability-disaggregated data to ensure that everyone's needs are addressed. ${ }^{19}$

This study thus builds on existing literature on IPV and disabilities through an analysis of baseline data from a randomised controlled trial (RCT) aiming to reduce IPV through a social norms intervention in three districts in Western and Central Nepal. The study aims to (1) document the prevalence of women ages 18-49 who report living with a disability, (2) examine the associations between the extent of disability and past-year IPV experiences, and (3) compare perceived social support available for IPV among women based on disability status.

\section{METHODS}

\section{Study design}

The current study used the baseline data from 'Change Starts at Home: A Cluster RCT of a Media and Community Engagement Behavior Change Strategy to Prevent IPV in Nepal' (NCT02942433). ${ }^{20}$ The study is being implemented by Equal Access International in collaboration with Emory University, George Mason University and local partner Vijaya Development Resource Centre (VDRC).

The research team selected three districts in NepalNawalparasi, Kapilvastu and Chitwan-because of their high IPV prevalence and the strong presence of VDRC. ${ }^{17}$ Within districts, 36 village development committees were selected in consultation with project partners. Two wards were randomly selected with probability proportionate to size methodology. Household lists in each ward comprised the study's sampling frame, and 1440 female participants were chosen using simple randomisation. Random numbers were generated in Excel, and the households with the 20 highest numbers were selected. Study eligibility criteria were ages 18-49 years old, married to a husband aged 18+, lived in the study area regularly and had spent the majority of the past year with their husband, had no relocation plans for 2 years, and no easily detectable physical or cognitive impairment that would preclude study participation. An additional 10 eligible women per ward $(n=36)$ were recruited to join the intervention programming, for a total sample of 1800 women.

The enumerators were trained extensively on data collection. The staff visited the selected households to introduce the study and invite women to provide written informed consent. The staff read consent statements in Nepali due to high rates of illiteracy in Nepal. Women with low literacy signed with an 'X'. A summary of consent and participants' rights were reiterated prior to survey administration. The baseline study was conducted in March 2016. The enumerators collected survey data 
Table 1 Items used to assess intimate partner violence (IPV), perceived social support for IPV and disability status

\begin{tabular}{|c|c|}
\hline Variables & Items \\
\hline Past-year physical and/or sexual violence & $\begin{array}{l}\text { In the past } 12 \text { months, how often has your husband slapped or thrown } \\
\text { something at you; pushed or shoved you; hit you with his fist or something else; } \\
\text { kicked, dragged, beaten, choked or burned you; threatened or actually used a } \\
\text { gun, knife or other weapon against you? } \\
\text { In the past } 12 \text { months, how often has your husband physically forced you to } \\
\text { have sex; made you feel afraid enough that you had sex when you did not want } \\
\text { to; forced you to do something sexual you did not want to? }\end{array}$ \\
\hline Past-year economic violence & $\begin{array}{l}\text { In the past } 12 \text { months, how often has your husband prevented you from } \\
\text { getting a job, going to work, trading/earning money; taken your earning or } \\
\text { valuables against your will; kept money from his earnings for alcohol, tobacco } \\
\text { or other things for himself when he knew you were having trouble affording the } \\
\text { household expenses? }\end{array}$ \\
\hline Perceived social support & $\begin{array}{l}\text { Do you strongly agree, somewhat agree, somewhat disagree, strongly disagree } \\
\text { to the following statements: } \\
\text { If your husband hit you or physically hurt you in any other way, a member of } \\
\text { your own (natal) family would tell your husband to stop. } \\
\text { If your husband hit you or physically hurt you in any other way, a member of } \\
\text { your husband's family would tell your husband to stop. }\end{array}$ \\
\hline Disability status & $\begin{array}{l}\text { Do you have no difficulty, some difficulty, a lot of difficulty or cannot do at all the } \\
\text { following: see, even if wearing glasses; hear; walk or climb steps; remember or } \\
\text { concentrate; speak. }\end{array}$ \\
\hline
\end{tabular}

using tablets and verbally read the survey questions in Nepali, and then selected onscreen answers on behalf of the participants. This study followed the international ethics standards on conducting intervention research on violence against women by, for instance, interviewing women in private spaces, only asking one member of a couple (in our case, women) about violence against women experiences, as opposed to both members, and training interviewers on how to recognise distress and on referral protocols. ${ }^{21}$ Additional study details have been published elsewhere. ${ }^{20}$

\section{Measures}

A five-item and three-item scale captured past-year physical and past-year sexual IPV, respectively, using the standard outcomes for assessment of IPV from the What Works to Prevent Violence Global Program. ${ }^{22}$ For items corresponding to each measure, see table 1 . We assessed emotional IPV via a four-item scale from the WHO Multi-Country Study on Women's Health and Domestic Violence, ${ }^{23}$ and past-year economic violence via the United Nations Multi-country Study on Men and Violence's three-item scale. ${ }^{24}$ For each item, responses included never, once, few, many and refuse to answer. Dichotomous variables were created for each IPV type and were coded as having experienced that violence if any scale item for that was answered 'once', 'few' or 'many'.
Variables were coded 'no' if participants responded 'never' to all items. ${ }^{25} 26$

Past-year in-law violence was assessed with two items developed for this study and based on the emotional and physical IPV items. A dichotomous variable was created and women who responded 'yes' to either question were coded as having experienced any in-law violence; all others were coded as 'no'.

To assess perceived social support from natal family or in-laws, women were asked two questions. Family or in-laws were considered (and coded) supportive if the woman responded strongly or somewhat agree and unsupportive if she answered somewhat/strongly disagree. Two dichotomous variables were created-one for the family and another for the in-laws. These measures were developed for this study and were based on the physical and emotional IPV items.

Five items of the Washington Group on Disability Statistics ${ }^{27}$ Short Set six-item scale were used to assess respondents' disability status. While dichotomous indicators of disability are the most common approach, we constructed a three-level categorical variable to capture the spectrum of impairment women living with disabilities may face. ${ }^{28}$ A woman was coded as living without a disability if she answered 'no difficulty' to all five items, living with a disability with some impairment if she answered 'some 
difficulty' to any of the five items, or living with a disability with severe impairment if she answered 'a lot of difficulty' or 'cannot do at all' to any of the five items.

Sociodemographic variables included a continuous measure of age and categorical measures of the number of children, education and husband's education (none, primary, secondary, college or higher), age at marriage, and advantaged versus disadvantaged caste. A single, dichotomous item assessed income stress, 'Are you or your husband frequently stressed because of not having enough income?'

\section{Analysis}

Descriptive statistics examined the frequencies of all variables. Bivariate associations using Pearson's $\chi^{2}$ tests assessed the associations between dichotomous sociodemographic variables and disability, the main predictor variable, and dichotomous sociodemographic variables and outcomes measures. t-Tests were used to for continuous demographic variables. Generalised estimating equations logistic regressions were used to assess the relationship between disability status and IPV experiences while accounting for data clustering. We ran unadjusted regressions with the three-level categorical disability variable and each outcome. We then ran adjusted logistic regressions, controlling for sociodemographic variables based on statistical and conceptual rationale. To preserve power in adjusted regressions, covariates were dichotomously coded. Ten observations had missing data; thus, 1790 were included in adjusted models. All analyses were conducted in Stata V.14.1.

\section{RESULTS}

\section{Demographics}

The sample consisted of 1800 women (mean age of 34.5 ; table 2$)$. One in three $(31.2 \%)$ reported no education, and husbands were more educated than the women ( $14.1 \%$ had no education). Half of the women $(52.9 \%)$ were from an advantaged caste; most women (79.7\%) had one to three children, and just under half (44.9\%) reported household income stress and marriage before age $18(48.4 \%)$.

\section{Prevalence of disability and bivariate associations with demographics}

Disability (some and/or severe impairment) was reported among $40.2 \%$ of women. Over a third $(35.3 \%)$ reported some impairment, while $4.9 \%$ reported severe impairment. Disability status was significantly associated with lower women and men's educational attainment $(p<0.001)$. Severe impairment was associated with younger age at marriage $(p=0.003)$, more children $(p<0.001)$ and household income stress $(p<0.001)$.

\section{Prevalence of past-year IPV and bivariate associations with demographics}

One in four (25.3\%) women reported past-year physical and/or sexual IPV. Separately, $15.7 \%$ reported past-year physical violence and $18.1 \%$ reported past-year sexual violence. Women with less education and lower husband education $(\mathrm{p}<0.001)$, from a disadvantaged caste $(\mathrm{p}<0.001)$, younger marriage age $(\mathrm{p}=0.002)$, more children $(p=0.037)$ and household income stress $(p<0.001)$ reported experiencing more physical and/or sexual IPV. Nearly one-third of the sample $(29.0 \%)$ had experienced past-year emotional IPV; sociodemographic associations mirrored observations regarding physical and/ or sexual IPV. Economic IPV was reported by $17.5 \%$ of women. Victimisation was significantly higher for women with less education $(\mathrm{p}=0.001)$, from a disadvantaged caste $(\mathrm{p}<0.001)$, married at a younger age $(\mathrm{p}=0.002)$, with husbands with less education $(\mathrm{p}=0.001)$ and with household income stress $(\mathrm{p}<0.001)$. Just over one in ten $(11.3 \%)$ women reported past-year in-law violence; disadvantaged caste $(\mathrm{p}=0.024)$ and household income stress $(\mathrm{p}<0.001)$ had significant associations (table 2$)$.

\section{Unadjusted and adjusted regression analyses of association between disability and past-year IPV}

As shown in table $3,37.1 \%$ of women living with a disability with severe impairment and $28.0 \%$ of women living with a disability with some impairment reported pastyear physical and/or sexual IPV compared with $22.8 \%$ of women without a disability. In the unadjusted model, compared with women with no disability, women with some and severe impairment were significantly more likely to report physical and/or sexual IPV $(\mathrm{OR}=1.29$, $95 \%$ CI 1.03 to 1.56 ; OR=1.87, 95\% CI 1.18 to 2.93 , respectively). Women with severe impairment also were more likely to experience physical and/or sexual IPV (adjusted OR (AOR) $=1.68,95 \%$ CI 1.04 to 2.72) than women with no disability in the adjusted model. A similarly elevated likelihood was observed among women with some impairment relative to no disability, but the differences were marginally insignificant $(\mathrm{AOR}=1.23$, $95 \%$ CI 0.96 to 1.56 ) (table 3 ).

Nearly half of women with severe impairment (41.6\%) and one in three women with some impairment (31.7\%) reported past-year emotional IPV, compared with $26.5 \%$ of women with no disabilities. Significant differences were observed between women with some or severe impairment and women without a disability in the unadjusted model (OR=1.29, 95\% CI 1.04 to 1.60 ; $\mathrm{OR}=1.90,95 \%$ CI 1.21 to 2.95 , respectively). Adjusted regressions revealed that, compared with women without a disability, women with severe impairment had greater odds of reporting past-year emotional IPV (AOR=1.65, 95\% CI 1.03 to 2.65). The likelihood was also higher among women with some impairment, relative to no disability; the difference, however, was marginally non-significant $(\mathrm{AOR}=1.20,95 \%$ CI 0.94 to 1.51 ).

One in five women with some impairment (20.6\%) and nearly one in four women with severe impairment $(23.6 \%)$ reported experiencing economic violence. Unadjusted regressions revealed significant differences between women with some $(\mathrm{OR}=1.47,95 \%$ CI 1.14 to 


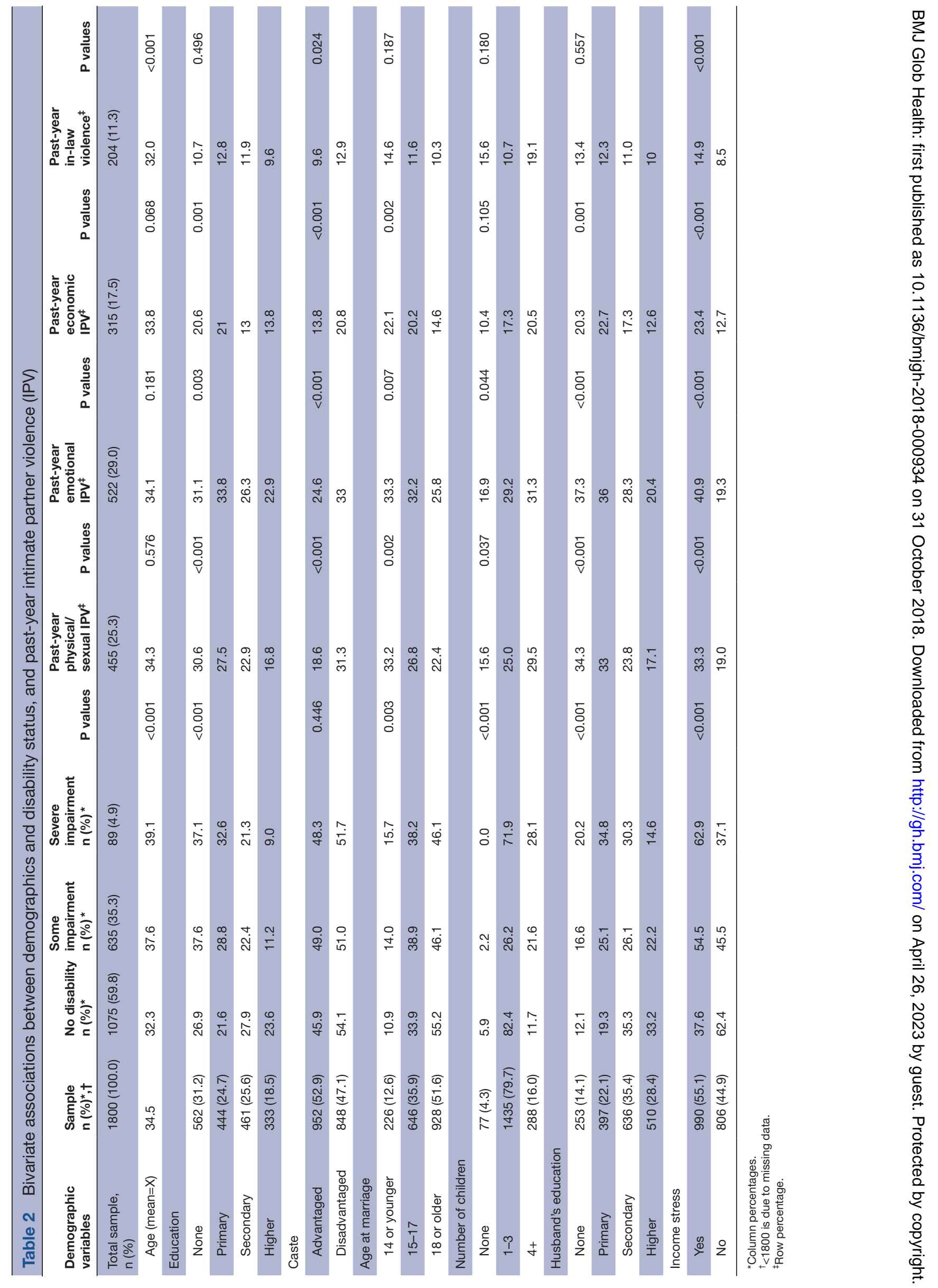




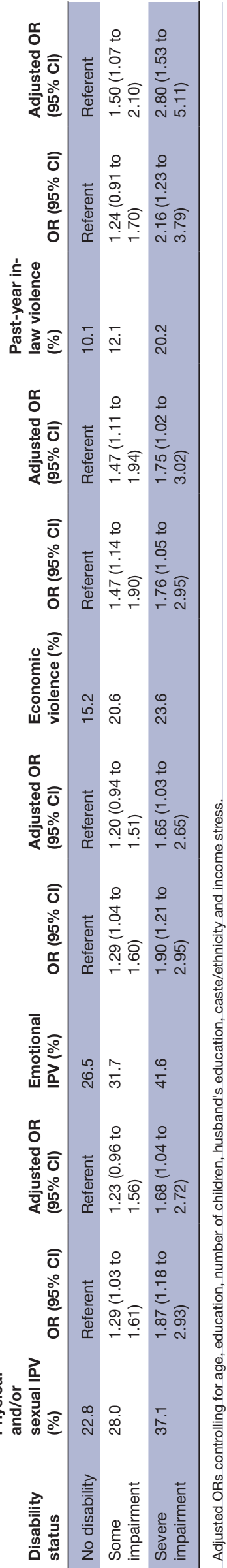

$1.90)$ or severe (OR=1.76, 95\% CI 1.05 to 2.95$)$ impairment and women without a disability. In the adjusted model, women with some impairment $(\mathrm{AOR}=1.47,95 \%$ CI 1.11 to 1.94 ) and with severe impairment (AOR=1.75, $95 \%$ CI 1.02 to 3.02 ) were significantly more likely to report economic IPV than women without a disability.

In-law violence was reported by $12.1 \%$ of women with some impairment and $20.2 \%$ of women with severe impairment, compared with $10.1 \%$ of those without a disability. In the unadjusted model, a significant difference was only observed between women with severe impairment and women without a disability $(\mathrm{OR}=2.16,95 \%$ CI 1.23 to 3.79 ); the difference between women with some impairment and without a disability was marginally insignificant ( $\mathrm{AOR}=1.24,95 \% \mathrm{CI} 0.91$ to 1.70 ). In the adjusted model, compared with women without a disability, those with some or severe impairment had greater odds of reporting past-year in-law violence (AOR $=1.50,95 \%$ CI 1.07 to 2.10; $\mathrm{AOR}=2.80,95 \%$ CI 2.53 to 5.11, respectively).

\section{Unadjusted and adjusted regression analyses of association between disability and perceived social support}

Among women with severe impairment, 86.5\% reported having a supportive (natal) family, compared with $92.4 \%$ of women with some impairment and $94.3 \%$ of women without a disability. In the unadjusted model, significant differences were observed between women with severe impairment and women without a disability $(\mathrm{OR}=0.93$, $95 \%$ CI 0.88 to 0.98 ). No statistically significant differences emerged in the adjusted model. Nearly seven in ten women $(69.7 \%)$ with severe impairment reported having supportive in-laws, as opposed to $81.6 \%$ of women with some impairment and $88.1 \%$ of women with no disability. Adjusted analyses revealed that women with some impairment and those with severe impairment were less likely to report having supportive in-laws than women without a disability $(\mathrm{AOR}=0.64,95 \%$ CI 0.48 to 0.86 ; $\mathrm{AOR}=0.34$, $95 \%$ CI 0.20 to 0.58 , respectively) (table 4 ).

\section{DISCUSSION}

In this cross-sectional, community-based analysis of married women residing in three districts in Nepal, disability status was associated with increased vulnerability to experiencing multiple forms of IPV. This finding is consistent with numerous studies comparing IPV experiences by disability status. ${ }^{67}$ Newer to this body of work is the observation of a gradient in impairment as it relates to IPV vulnerability. Findings revealed that women living with a disability who reported severe impairment also were more likely to report multiple forms of IPV and violence from in-laws, relative to women living with a disability reporting some impairment. Similarly, women with some impairment were more likely to report some forms of IPV than women without any disability. The findings mirror preliminary baseline analyses from two other What Works IPV prevention RCTs. ${ }^{28}$ 
Table 4 Unadjusted and adjusted logistic regressions for associations between disability status and having families or inlaws supportive in the context of intimate partner violence

\begin{tabular}{|c|c|c|c|c|c|c|}
\hline Disability status & $\begin{array}{l}\text { Supportive } \\
\text { family }(N=1800)\end{array}$ & OR (95\% Cl) & $\begin{array}{l}\text { Adjusted OR } \\
(95 \% \mathrm{Cl})\end{array}$ & $\begin{array}{l}\text { Supportive in- } \\
\text { laws ( } N=1800)\end{array}$ & OR $(95 \% \mathrm{Cl})$ & $\begin{array}{l}\text { Adjusted OR } \\
(95 \% \mathrm{Cl})\end{array}$ \\
\hline No disability & 94.3 & Referent & Referent & 88.1 & Referent & Referent \\
\hline $\begin{array}{l}\text { Some } \\
\text { impairment }\end{array}$ & 92.4 & $\begin{array}{l}0.98 \text { (0.96 to } \\
1.01)\end{array}$ & $\begin{array}{l}0.91(0.60 \text { to } \\
1.37)\end{array}$ & 81.6 & $\begin{array}{l}0.94(0.90 \text { to } \\
0.97)\end{array}$ & $\begin{array}{l}0.64(0.48 \text { to } \\
0.86)\end{array}$ \\
\hline $\begin{array}{l}\text { Severe } \\
\text { impairment }\end{array}$ & 86.5 & $\begin{array}{l}0.93 \text { (0.88 to } \\
0.98)\end{array}$ & $\begin{array}{l}0.52(0.26 \text { to } \\
1.05)\end{array}$ & 69.7 & $\begin{array}{l}0.83(0.77 \text { to } \\
0.90)\end{array}$ & $\begin{array}{l}0.34 \text { (0.20 to } \\
0.58)\end{array}$ \\
\hline
\end{tabular}

While more research is needed to better understand the mechanisms underlying these patterns, the gradient is consistent with social epidemiological research documenting social gradients in health outcomes and behaviours, where social gradients relate to inequalities in social status. ${ }^{29}$ In Nepal, research has documented social norms and social inequities that are detrimental to women. ${ }^{30}$ Such gender inequities may be compounded with greater impairment levels. Increased levels of disability may create higher degrees of dependency on partners and family and therefore greater social inequity between a woman living with a disability, and her male partner, and other family members. ${ }^{8} 30$ Such dependence, along with endorsement of harmful gender norms, acceptance of IPV, stigma against disability status and lack of socially inclusive services may thus account for the observed gradient. ${ }^{8}$

Notably, while a gradient in the prevalence of IPV experiences was uniformly observed, statistically significant differences did not consistently emerge across all IPV forms. For instance, for all forms of IPV, women with severe impairment were also significantly more likely to report higher levels of IPV experiences. However, significant differences in IPV experiences between women reporting some impairment versus no disability were only observed for economic IPV and in-law violence. It may be that experiencing fewer impairments makes women slightly less vulnerable to IPV experiences due to greater ability to access services without assistance from partners/family members and more ability to fulfil traditional gendered expectations (eg, housework, cooking, engaging in sexual activity). ${ }^{11}$ Regardless, the reporting of IPV experiences was still elevated in this group, and thus more research is needed to better understand the observed patterns.

In addition to reporting of IPV experiences, the current study is among only a few to examine how perceived social support for IPV from family members may vary by disability status. While overall perceptions of social support were high, relative to women without disabilities, women with disabilities reported lower perceptions of having support from family (both natal and in-laws) if IPV were to occur. Women reporting severe impairment were the least likely to perceive having this support. Interestingly, perceived social support also varied by family type. Women with some impairment and women without disability did not differ in perceived social support from their natal family. However, women with some impairment were significantly less likely to report perceived support from in-laws in comparison with counterparts without any disability; women with severe disability reported even lower levels of perceived social support from in-laws. As previously noted, a similar pattern was also observed regarding violence perpetration from in-laws in the current study. Collectively, these findings are consistent with existing research within South Asia showcasing how husbands' family members contribute to IPV by perpetrating such violence and, more commonly, remaining complicit and/or encouraging a husbands' abuse. $^{15}$ It may be that family members, particularly in-laws, are also the main providers of day-to-day support for women with both some and severe disabilities. ${ }^{10}$ Thus, if caregiving family members are simultaneously perpetrating violence, then women with disabilities would not perceive them as supportive.

Future research is needed regarding the help-seeking behaviours of women living with disabilities in Nepal. It is currently unclear whether lower perceived social support from family members would be predictive of less helpseeking for IPV among informal resources. Multicountry data from low- and middle-income countries (LMICs) document how help-seeking from informal resources is more frequently reported than more formal resources. ${ }^{23}$ Findings from a UK-based study found that people living with chronic mental illness and IPV were more likely to seek help from formal resources (eg, health professionals) as opposed to informal sources. ${ }^{31}$ Within such higher income countries, agencies serving IPV victims face numerous barriers in funding, training and facilities to properly assist women with disabilities. ${ }^{32}$ These challenges within lower income countries, such as Nepal, are exacerbated, ${ }^{33}$ and thus underscore the importance of strengthening resources for women living with disabilities with IPV experiences.

There are study limitations. This study is cross-sectional; thus, the extent to which women's disabilities preceded the IPV (and was not caused by IPV) cannot be determined. This study also used an abridged version of the Washington Group's scale for disability statistics, ${ }^{27}$ and women with a severe cognitive impairment were excluded from the trial. ${ }^{20}$ Thus, disability prevalence may be underestimated and not reflect a fuller spectrum of 
disability experiences. This scale was not previously validated in Nepal, specifically. However, the scale was developed among a consortium of international partners, designed as a cross-culturally comparable measure of disability, and is being used in demographic and health surveys in other LMICs. ${ }^{27}$ Furthermore, this study used one approach to capturing impairment on a spectrum. Future research should examine the optimal way to capture this range of impairment. In addition, IPV experiences may be under-reported despite the study team's efforts to establish rapport and ensure confidentiality. This study uses baseline data from a larger RCT that aims to change gender norms and reduce IPV. ${ }^{20} \mathrm{~A}$ criterion for this trial was that women would have permission from their husbands to participate. Thus, despite the high levels of IPV reported herein, more severe IPV experiences may not be included.

Limitations notwithstanding, this study is among a few to establish the relationship between disability and IPV in a low-income country context. Such work, particularly in Nepal, is important given the vulnerability to disability and impairments resulting from natural disasters and conflicts. ${ }^{34}$ In 2015, an earthquake in Nepal killed 9000 people and injured $22000 .^{35}$ Additionally, the government of Nepal ratified the United Nations Convention on the Rights of Persons with Disabilities in $2010^{36}$ and in 2015 enacted a new provision for people with disabilities as part of Nepal's new constitution. ${ }^{37}$ Although this legislation protects people with disabilities from discrimination and demands equal access to education, public services, transportation and political participation, more work is needed to address the specific needs of women with disabilities experiencing IPV. Safe and equal access to programmes serving victims of IPV for women with disabilities are needed. In concert with this effort, there should be an improvement in strategies for identifying women living with disabilities who are experiencing IPV and are often socially isolated. Within clinical settings, healthcare providers could integrate universal IPV education and screening when providing care to patients living with a disability. Screenings should take into consideration the different types of impairment to allow patients the means to disclose. Further, because women with disabilities may be accompanied to appointments by partners and family members and/or rely on family members/partners for transportation, screenings should be conducted in a way that preserves their privacy and does not put them in greater danger. Future research, including qualitative work, is needed to examine the mechanisms that underlie the observed gradients regarding disability status, IPV and perceptions of social support. Such research may consider the importance of both visible and invisible disabilities, in addition to severity, as it relates to IPV vulnerability. Future research should also examine how intersecting social marginalisation, such as disability status and gender, in addition to lower socioeconomic status, may increase vulnerability to IPV. Latent class analysis (LCA) is increasingly used to advance both the understanding of social risk factors pertaining to IPV vulnerability ${ }^{38}$ and the intersectionality of multiple forms of social marginalisation on health behaviours. ${ }^{39}$ Thus, LCA may offer insight for IPV vulnerability among women with disabilities in Nepal. Moreover, as intervention research on the prevention of IPV in LMICs grows, it is critical to examine potential differential impacts on women living with disabilities. This may be particularly important given the current study's findings showcasing how severe impairment was associated with younger age at marriage. The needs of women living with disabilities should be integrated into ongoing IPV prevention and intervention work to destigmatise disability status and ensure services are accessible to women with disabilities. More accessible, more inclusive prevention and response would help ensure that 'no one is left behind'. ${ }^{40}$

Contributors JG and CJC conceptualised the study. CJC, GF and BS led the data collection. JG and LFC conducted data analysis. CJC and NG provided guidance on analysis and interpretation, and JG, LFC and CJC drafted the manuscript. CJC is the PI of the study from which these data were obtained. All authors contributed feedback and provided approval of the final manuscript.

Funding This document is an output from the What Works to Prevent Violence: A Global Programme, which is funded by the UK Aid from the UK Department for International Development (DFID) for the benefit of low-income and middleincome countries (https://www.gov.uk/government/organisations/department-forinternational-development). The grant number is P06254.

Disclaimer The views expressed and the information contained in it are not necessarily those of or endorsed by the DFID, which can accept no responsibility for such views or information or for any reliance placed on them.

Competing interests None declared.

Patient consent Not required.

Ethics approval This study received Institutional Review Board approvals from Emory University, George Mason University and the Nepal Health Research Council.

Provenance and peer review Not commissioned; externally peer reviewed.

Data sharing statement № additional data are available.

Open access This is an open access article distributed in accordance with the Creative Commons Attribution Non Commercial (CC BY-NC 4.0) license, which permits others to distribute, remix, adapt, build upon this work non-commercially, and license their derivative works on different terms, provided the original work is properly cited, appropriate credit is given, any changes made indicated, and the use is non-commercial. See: http://creativecommons.org/licenses/by-nc/4.0/

\section{REFERENCES}

1. World Health Organization, 2011. World report on disability. Available from: http://www.who.int/disabilities/world_report/2011/report.pdf [accessed 25 Apr 2018].

2. Emerson E, Madden R, Graham H, et al. The health of disabled people and the social determinants of health. Public Health 2011;125:145-7.

3. Filmer D. Disability, poverty, and schooling in developing countries: results from 14 household surveys. The World Bank Economic Review 2008;22:141-63.

4. Parish SL, Grinstein-Weiss M, Yeo YH, et al. Assets and income: disability-based disparities in the United States. Soc Work Res 2010;34:71-82.

5. Mithen J, Aitken Z, Ziersch A, et al. Inequalities in social capital and health between people with and without disabilities. Soc Sci Med 2015;126:26-35

6. Brownridge DA. Partner violence against women with disabilities: prevalence, risk, and explanations. Violence Against Women 2006;12:805-22.

7. Hahn JW, McCormick MC, Silverman JG, et al. Examining the impact of disability status on intimate partner violence victimization in a population sample. J Interpers Violence 2014;29:3063-85. 
8. Puri M, Misra G, Hawkes S. Hidden voices: prevalence and risk factors for violence against women with disabilities in Nepal. BMC Public Health 2015;15:261.

9. Aryal N. Silent screams: a study on the sexual violence against blind women of the Kathmandu Valley. Kathmandu, Nepal: Unpublished Report Tribhuwan University and Action Aid Nepal, 2004.

10. Rashid S, Daruwalla N, Puri M, 2012. Count me in. research report: violence against disabled, lesbian, and sexworking women in Bangladesh, India, and Nepal. Available from: http://www.creaworld. org/sites/default/files/The\%20Count\%20Me\%20In!\%20Research\% 20Report.pdf [accessed 25 Apr 2018].

11. Naved RT, Blum LS, Chowdhury S, et al. Violence against women with chronic maternal disabilities in rural Bangladesh. $J$ Health Popul Nutr 2012;30:181.

12. Daruwalla N, Chakravarty S, Chatterji S. Violence against women with disability in Mumbai, India: a qualitative study. Sage open 2013:3:2158244013499144.

13. Marmot M, Friel S, Bell R, et al. Closing the gap in a generation: health equity through action on the social determinants of health. The Lancet 2008;372:1661-9.

14. Mitra S, Posarac A, Vick B. Disability and poverty in developing countries: a multidimensional study. World Dev 2013;41:1-18.

15. Silverman JG, Balaiah D, Ritter J, et al. Maternal morbidity associated with violence and maltreatment from husbands and in-laws: findings from Indian slum communities. Reprod Health 2016;13:109.

16. Sylaska KM, Edwards KM. Disclosure of intimate partner violence to informal social support network members: a review of the literature. Trauma Violence Abuse 2014;15:3-21.

17. Ministry of Health and Population (MOHP) [NEPAL], New ERA, ICF International Inc. Nepal demographic and health survey. Family health division, dept. Of health service, ministry of health, his majesty's Govt 2011.

18. Atteraya MS, Gnawali S, Song IH. Factors associated with intimate partner violence against married women in Nepal. $J$ Interpers Violence 2015;30:1226-46.

19. United Nations. Disability inclusive sustainable development goals. Available from: http://www.un.org/disabilities/documents/sdgs/ disability_inclusive_sdgs.pdf [Accessed 1 Nov 2017].

20. Clark CJ, Spencer RA, Shrestha B, et al. Evaluating a multicomponent social behaviour change communication strategy to reduce intimate partner violence among married couples: study protocol for a cluster randomized trial in Nepal. BMC Public Health 2017;17:75.

21. World Health Organization, 2016. Ethical and safety recommendations for intervention research on violence against women. building on lessons from WHO's Putting women first: ethical and safety recommendations for research on domestic violence against women. Available from: http://apps.who.int/iris/bitstream/ handle/10665/251759/9789241510189-eng.pdf?sequence $=1$ [accessed 25 Apr 2018]

22. What Works to Prevent Violence Global Program. Standard outcomes for assessment of intimate partner violence. 2015

23. García-Moreno C, Jansen H, Ellsberg M. WHO Multicountry study on women's health and domestic violence against women: summary report of initial results on prevalence, health outcomes and women's responses. Geneva: World Health Organization, 2017.

24. Fulu E, Warner X, Miedema S. Toolkit for replicating the un multicountry study on men and violence: Understanding why some men use violence against women and how we can prevent it. Bangkok: UNDP. Available from: http://www.partners4prevention.org/sites/ default/files/p4p-unmcr-step-guide.pdf [accessed 20 August 2017].

25. Garcia-Moreno C, Jansen HA, Ellsberg M, et al. Prevalence of intimate partner violence: findings from the WHO multi-country study on women's health and domestic violence. Lancet 2006;368:1260-9.

26. Garcia-Moreno C, Pallitto C, Devries K. Global and regional estimates of violence against women: prevalence and health effects of intimate partner violence and non-partner sexual violence. Geneva: World Health Organization, 2013.

27. Washington Group on Disability Statistics, 2017. The washington group short set on functioning. Available from: http://www. washingtongroup-disability.com/wp-content/uploads/2016/12/WGDocument-2-The-Washington-Group-Short-Set-on-Functioning.pdf [accessed 17 Nov 2017].

28. van der Heijden I, Dunkle K, 2017. What works evidence review: preventing violence against women and girls with disabilities in lower- and middle-income countries (LMICs). Available from: http:// whatworks.co.za/documents/publications/114-disability-evidencebrief-new-crop-3/file [accessed 17 Nov 2017].

29. Marmot M. Social determinants of health inequalities. The Lancet 2005;365:1099-104.

30. Clark CJ, Ferguson G, Shrestha B. Social norms and women's risk of intimate partner violence in nepal social science \& medicine.

31. Khalifeh H, Oram S, Trevillion K, et al. Recent intimate partner violence among people with chronic mental illness: findings from a national cross-sectional survey. Br J Psychiatry 2015;207:207-12.

32. Chang JC, Martin SL, Moracco KE, et al. Helping women with disabilities and domestic violence: strategies, limitations, and challenges of domestic violence programs and services. J Womens Health 2003;12:699-708.

33. World Health Organization, 2009. Promoting sexual and reproductive health for persons with disabilities. Available from: https://www. unfpa.org/sites/default/files/pub-pdf/srh for disabilities.pdf [accessed 25 Apr 2018].

34. Mallick M, Aurakzai J, Bile K, 2010. Large-scale physical disabilities and their management in the aftermath of the 2005 earthquake in Pakistan. Available from: http://applications.emro.who.int/emhj/V16/ supp/16_S_2010_098_105.pdf [accessed 25 Apr 2018].

35. NPC, 2015. Post disaster needs assessment. Excutive summary. Government of Nepal national planning commission25 Apr 2018). Available from: http://www.worldbank.org/content/dam/Worldbank/ document/SAR/nepal-pdna-executive-summary.pdf

36. United Nations, 2018. Convention on the Rights of Persons with Disabilities (CRPD). Available from: https://www.un.org/ development/desa/disabilities/convention-on-the-rights-of-personswith-disabilities.html [accessed 12 Jul 2012].

37. Constitution of Nepal, 2015. Available from: http://www.refworld.org/ docid/561625364.html [accessed 30 Nov 2017].

38. Sipsma HL, Falb KL, Willie T, et al. Violence against Congolese refugee women in Rwanda and mental health: a cross-sectiona study using latent class analysis. BMJ Open 2015;5:e006299.

39. Garnett BR, Masyn KE, Austin SB, et al. The intersectionality of discrimination attributes and bullying among youth: an applied latent class analysis. J Youth Adolesc 2014:43:1225-39.

40. UN Women. Making the SDGs Count for women and girls with disabilities. Available from: http://www.unwomen.org/-/media/ headquarters/attachments/sections/library/publications/2017/ making-sdgs-count-for-women-with-disabilities. pdf?la=en\&vs=2823 